Basuki

Jurnal JIPS (Jurnal Ilmiah Pendidikan Scholastic) Vol. 4 No. 3 (2020) ISSN : 2579-5449

Terbit online pada laman web jurnal : http://e-journal.sastra-unes.com/index.php/JIPS

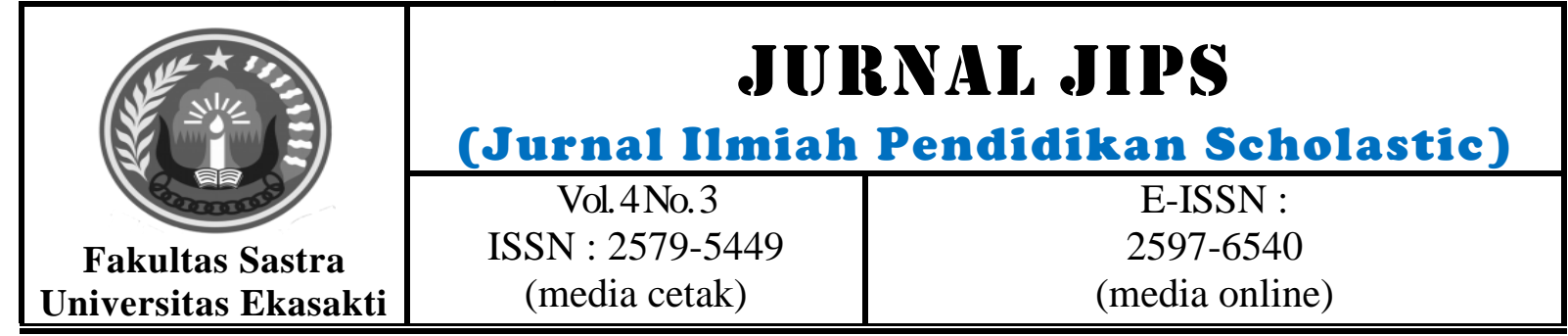

\title{
UPAYA PENINGKATAN KEMAMPUAN GURU DALAM MENGGUNAKAN ALAT PERAGA MATEMATIKA MELALUI IN HOUSE TRAINING (IHT) DI SD NEGERI O6 TIMPEH TAHUN 2020
}

\author{
Basuki \\ SDN 06 Timpeh
}

\begin{abstract}
Penelitian Tindakan Sekolah yang dilakukan bertujuan untuk peningkatan terhadap kemampuan guru SDN 06 Timpeh dalam menggunakan alat peraga melalui kegiatan IHT. Dari hasil observasi awal, diketahui bahwa guru kurang mampu alat peraga matematika pada proses pembelajaran matematika, hal ini disebabkan kurangnya pemahaman terhadap guru untuk memanfaatkan sarana alat peraga pada proses pembelajaran. Oleh sebab itu peneliti mengadakan kegiatan pelatihan terhadap guru SDN 06 Timpeh dalam memanfaatkan alat peraga yang bisa dipergunakan pada proses pembelajaran Penelitian ini menggunakan Penelitian Tindakan Sekolah (PTS) yang terdiri dari 2 tahap yaitu siklus I dan siklus 2. Adapun tiap siklus terdiri dari empat prosedur yaitu Perencanaan (Planning), Pelaksanaan tindakan (Acting), Observasi (Observing) dan Refleksi (Reflecting). Dengan subjek penelitian yaitu guru SDN 06 Timpeh sebanyak 10 orang guru kelas. Pada siklus I nilai rata-rata dari keseluruhan indikator memperoleh 72,09 dan meningkat pada siklus II menjadi 94,58. Jadi, terjadi peningkatan 22,49 dari siklus I. Dari pelaksanaan kegiatan yang dilakukan tersebut terlihat bahwa meningkatnya kemampuan guru dalam membuat alat peraga sesudah diterapkan kegiatan pendampingan.
\end{abstract}

Keywords: Kompetensi Guru, Alat Peraga, IHT

(C) 2020Jurnal JIPS

\section{INTRODUCTION}

Matematika merupakan salah satu pelajaran wajib yang ditempuh oleh anak mulaiusia Sekolah Dasar hingga tingkat menengah. Matematika memiliki objek kajian yang abstrak sehingga di dalam pembelajaran dibutuhkan alat bantu yang dapat memudahkan anak dalam memahami materi tersebut. Penggunaan Alat peraga matematika dapat digunakan untuk membantu kesulitan anak dalam memahami suatu materi tertentu, terutama pada pembelajaran Matematika.

Alat peraga matematika juga dapat membantu guru dalam penyampaikan materi kepada anak yang memiliki kebutuhan khusus. Berdasarkan hasil observasi, keterbatasan alat peraga matematika yang disediakan oleh sekolah menjadi kendala bagi guru dalam menyampaikan materi kepada anak. Oleh sebab itu, permasalahan tersebut layak untuk segera disikapi

Bentuk pembelajaran di kelas terkadang membuat anak kurang tertarik dan mudah bosan. Oleh karenanya guru perlu mencari alternatif yang inovatif dan menarik sehingga pembelajaran dapat diberikan secara optimal. Terlebih untuk anak berkebutuhan khusus 
dimana mereka membutuhkan pendampingan dan perlakuan khusus untuk dapat menyeimbangkan kemampuan akademiknya dengan anak yang tidak mengalami kebutuhan khusus. Ketika pihak sekolah kurang memberikan perhatian dan penanganan yang tepat dan sesuai untuk anak berkebutuhan khusus, maka hal tersebut dapat semakin mempersulit dalam memahami pelajaran atau

\section{RESEARCH METHODS}

Pada pelaksanaan kegiatan penelitian tindakan sekolah ini yang dijadikan subyek dalam penelitian adalah guru pada SDN 06 Timpeh Kecamatan Timpeh Kabupaten Dharmasraya yang merupakan tempat peneliti bertugas saat ini menjadi kepala sekolah pada tahun pelajaran 2019-2020. Adapun data guruguru yang ditunjuk dalam pelaksanaan penelitian tindakan sekolah ini sebagai berikut :

Tabel 3.1 Daftar Peserta

\begin{tabular}{|c|c|c|c|}
\hline 0 & $\begin{array}{l}\text { Nama } \\
\text { Guru }\end{array}$ & $\begin{array}{l}\text { Jenis } \\
\text { Guru }\end{array}$ & $\begin{array}{c}\text { Tu } \\
\text { Mas } \\
\text { Mengajar }\end{array}$ \\
\hline & $\begin{array}{l}\text { Musnar, } \\
\text { A.Ma.Pd }\end{array}$ & $\begin{array}{l}\text { Guru } \\
\text { Kelas }\end{array}$ & VI \\
\hline & $\begin{array}{l}\text { Amiruddin } \\
\text { Syarif, A.Ma.Pd }\end{array}$ & $\begin{array}{l}\text { Guru } \\
\text { Kelas }\end{array}$ & $\mathrm{B}^{\mathrm{II}}$ \\
\hline & Patra, S.Pd & $\begin{array}{l}\text { Guru } \\
\text { Kelas }\end{array}$ & $\mathrm{A}^{\mathrm{IV}}$ \\
\hline & $\begin{array}{l}\text { Nurbandiy } \\
\text { ah, S.Pd }\end{array}$ & $\begin{array}{l}\text { Guru } \\
\text { Kelas }\end{array}$ & $\mathrm{A}^{\mathrm{V}}$ \\
\hline & $\begin{array}{ll}\text { Minarti, } \\
\text { S.Pd }\end{array}$ & $\begin{array}{l}\text { Guru } \\
\text { Kelas }\end{array}$ & I A \\
\hline & $\begin{array}{l}\text { Nurhariyas } \\
\text { ni, S.Pd }\end{array}$ & $\begin{array}{l}\text { Guru } \\
\text { Kelas }\end{array}$ & $\mathrm{A}^{\mathrm{II}}$ \\
\hline & $\begin{array}{c}\text { Eva } \\
\text { Yusmarni, S.Pd }\end{array}$ & $\begin{array}{l}\text { Guru } \\
\text { Kelas }\end{array}$ & $\mathrm{A}^{\mathrm{III}}$ \\
\hline & $\begin{array}{c}\text { Irvan } \\
\text { Hilmawan, S.Pd }\end{array}$ & $\begin{array}{l}\text { Guru } \\
\text { Kelas }\end{array}$ & $\mathrm{B}^{\mathrm{V}}$ \\
\hline & $\begin{array}{cr}\text { ZP. } & \text { Fitri } \\
\text { Ramadhona, } & \text { S.Pd }\end{array}$ & $\begin{array}{l}\text { Guru } \\
\text { Kelas }\end{array}$ & \\
\hline 0 & $\begin{array}{l}\text { Denovaldi, } \\
\text { S.Pd }\end{array}$ & $\begin{array}{l}\text { Guru } \\
\text { Kelas }\end{array}$ & $\mathrm{B}^{\mathrm{IV}}$ \\
\hline
\end{tabular}

Sumber: Profil SDN 06 Timpeh Tahun Ajar 2019/2020.

\section{A. Setting Penelitian}

materi. Anak berkebutuhan khusus memerlukan benda-benda konkrit untuk membantu memahami suatu materi pembelajaran. Kurangnya penggunaan benda-benda konkrit dalam setiap pembelajaran menjadikan suatu hambatan guru dalam menyampaikan materi. Guru hanya menjelaskan berulang-ulang hingga dirasa mereka dapat memahami suatu materi.

Pada setting penelitian terhadap menggunakan alat peraga matematika meliputi tempat pelaksanaan, waktu penelitian, jadwal penelitian dan tahapan penelitian diuraikan sebagai berikut :

1. Waktu dan Tempat pelaksanaan

Penelitian Tindakan Sekolah ini dilakukan pada semester satu tahun 2020 dengan subyeknya guru di SDN 06 Timpeh. Pada Penelitian Tindakan Sekolah dalam menggunakan alat peraga matematika dilaksanakan di tempat bertugas penulis sendiri yaitu SDN 06 Timpeh

2. Jadwal penelitian

Penelitian Tindakan Sekolah ini dilakukan selama dua bulan yang dimulai dari bulan Januari sampai dengan bulan Maret 2020

\section{B. TEKNIK PENGUMPULAN}

DATA

Cara pengumpulan data pada penelitian ini adalah dengan mengisi setiap Lembar pengamatan kemampuan terhadap guru dalam menggunakan alat peraga matematika

\section{TEKNIK ANALISIS DATA \\ 1. Teknik}

Teknik pengumpulan data pada proses penelitian ini dengan cara memberikan bimbingan dan arahan serta membimbing terhadap guru dalam menciptakan alat peraga matematika.

\section{Alat Pengumpulan Data}

Alat pengumpulan data dalam PTS ini sebagai berikut.

a.Wawancara menggunakan panduan wawancara untuk mengetahui kemampuan dalam menggunakan alat peraga matematika. 
b. Observasi menggunakan lembar observasi untuk mengetahui komponen apa saja yang diketahui guru dalam menggunakan alat peraga matematika.

c.Diskusi dilakukan dengan maksud untuk sharing pendapat antara peneliti dengan guru.

\section{Rancangan Penelitian}

1. Tindakan dilaksanakan dalam tahapan 2 siklus

2. Kegiatan dilaksanakan dalam semester ganjil tahun pelajaran 2019/2020.

3. Lama penelitian 4 pekan efektif dilaksanakan mulai tanggal 15 Januari 2020 sampai dengan 24 Maret 2020.

4. Dalam pelaksanaan tindakan,rancangan dilakukan dalam 2 siklus yang meliputi ; (a) perencanaan,(2) pelaksanaan, (3) observasi, (4) refleksi.

Hal-hal penting yang harus diperhatikan dalam Penelitian Tindakan Sekolah, menurut Sudarsono, F.X, (1999:2) yakni:

$1 . \quad$ Rencana

Tindakan apa yang akan dilakukan untuk meningkatkan kemampuan guru dalam menggunakan alat peraga matematika.

2.

Pelaksanaan

Apa yang dilakukan oleh peneliti sebagai upaya meningkatkan kemampuan guru dalam menggunakan alat peraga matematika.

3. Observasi

Peneliti melakukan pengamatan terhadap pelaksanaan pembuatan alat peraga matematika untuk mengetahui sejauh mana kemampuan guru dalam menggunakan alat peraga matematika. Selain itu juga peneliti mencatat hal-hal yang terjadi dalam pertemuan dan wawancara. Rekaman dari pertemuan dan wawancara akan digunakan untuk analisis dan komentar kemudian.
4.
Refleksi:
Peneliti

mengkaji, melihat, dan mempertimbangkan hasil atau dampak dari tindakan yang telah dilakukan. Berdasarkan hasil dari refleksi ini, peneliti bersama guru melaksanakan revisi atau perbaikan terhadap kemampuan guru dalam menggunakan alat peraga matematika.

Prosedur penelitian adalah suatu rangkaian tahap-tahap penelitian dari awal sampai akhir. Penelitian ini merupakan proses pengkajian sistem berdaur sebagaimana kerangka berpikir yang dikembangkan oleh Suharsimi Arikunto dkk (2006). Prosedur ini mencakup tahap-tahap: (1) perencanaan, (2) pelaksanaan, (3) pengamatan, dan (4) refleksi. Keempat kegiatan tersebut saling terkait dan secara urut membentuk sebuah siklus. Penelitian Tindakan Sekolah merupakan penelitian yang bersiklus, artinya penelitian dilakukan secara berulang dan berkelanjutan sampai tujuan penelitian dapat tercapai.

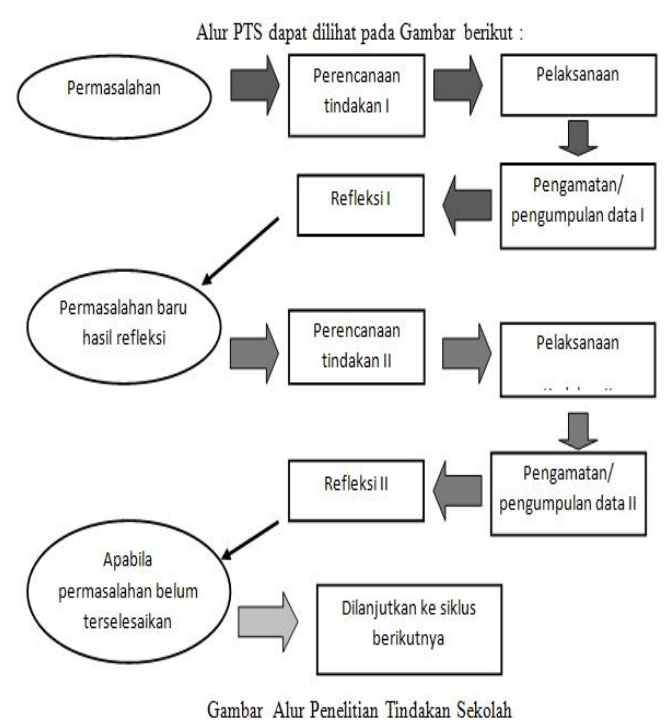

Gambar Alur Penelitian Tindakan Sekolah

\section{E. Rencana Pelaksanaan}

\section{Kegiatan}

Kegiatan dilaksanakan dalam tahapan dua siklus yaitu:

1. Siklus Pertama (Siklus I)

a.Peneliti merencanakan tindakan pada siklus I dengan membuat lembar pengamatan terhadap pelaksanaan kegiatan penelitian, selanjutnya membuat instrumen wawancara dan membuat rekapitulasi hasil dari pelaksanaan kegiatan pelatihan.

b. Memberikan apresiasi terhadap guru pada saat prosedur pelaksanaan penelitian dalam menggunakan alat peraga matematika

c.Memberikan materi terhadap pelaksanaan kegiatan pembuatan alat peraga matematika.

d. Memberikan bimbingan dan arahan pada saat proses penelitian. 
e.Peneliti melakukan observasi terhadap hasil penggunaan alat peraga matematika.

f. Melakukan perbaikan ketahap siklus II.

2. $\quad$ Siklus Kedua (Siklus II)

a.Pada tahap siklus II sama halnya dengan siklus I yaitu membuat lembar pengamatan terhadap pelaksanaan, instrumen wawancara dan membuat rekapitulasi hasil dari pelaksanaan kegiatan pelatihan

b. Peneliti melaksanakan tindakan sesuai dengan rencana pada siklus II.

\section{F. Indikator Pencapaian Hasil}

\section{RESULTS AND DISCUSSIONS}

Pada pelaksanaan kegiatan tahap siklus I, kegiatan ini dilakukan dengan 4 metode yakninya :

a.Perencanaan

1) Membuat instrumen pengamatan pada proses penelitian

2) Membuat lembar wawancara

b. Pelaksanaan

Pada tahap siklus I indikator pencapaian hasil dari setiap indikator pengukuran kemampuan peserta ditemukannya masih ada yang belum memenuhi kriteria mencukupi. Hal ini dibuktikan masih adanya beberapa guru kurang mampu menggunakan alat peraga matematika sesuai dengan materi pembelajaran.

c.Observasi

Observasi pada kegiatan ini dilakukan pada hari Rabu tanggal 15 Januari 2020, dari semua guru yang ditinjau dari pelaksanaan kegiatan tahap siklus I ternyata masih ada beberapa orang guru yang kurang mampu dalam menggunakan alat peraga pada pelajaran matematika. Hal ini terlihat dari kurang sesuainya alat peraga yang sesuai dengan matei pembelajaran.

\section{d. Tindak Lanjut}

Dari hasil yang didapatkan dari pelaksanaan kegiatan tahap siklus I. Dinyatakannya masih kurang berhasilnya kegiatan penelitian dilakukan, hal ini terlihat masih ada beberapa orang guru kurang mampu menyesuaikan materinya dengan alat peraga
Indikator keberhasilan dilihat dari observasi terhadap hasil penelitian, berikut hasil yang dinilai dari proses pelaksanaan penelitian:

1. Pemahaman dalam menggunakan alat peraga matematika

2. Berkreasi dalam menggunakan alat peraga matematika

3. Mampu menggunakan alat peraga matematika sesuai dengan materi pembelajaran

4. Memahami teknik dalam menggunakan alat peraga matematika

Mampu memanfaatkan bahan bekas menjadi alat peraga matematika

matematika yang telah dibuat. Untuk meningkatkan kemampuan terhadap guru tersebut, maka dilaksanakan tahap siklus II. Berikut hasil pelaksanaan kegiatan pendampingan pada tahapan siklus I.

Tabel 4.1 Hasil Kegiatan Tahap Siklus I

\begin{tabular}{|c|c|c|c|}
\hline o & Nama Guru & $\begin{array}{r}\mathbf{S i} \\
\text { klus I }\end{array}$ & $\begin{array}{l}\text { Klas } \\
\text { ifikasi }\end{array}$ \\
\hline & $\begin{array}{c}\text { Musnar, } \\
\text { A M M }\end{array}$ & 62 & $\mathrm{Cu}$ \\
\hline & $\begin{array}{l}\text { Amiruddin } \\
\text { Syarif, A.Ma.Pd }\end{array}$ & $7^{66}$ & $\mathrm{Cu}$ \\
\hline & Patra, S.Pd & 87 & $\mathrm{Sa}$ \\
\hline & Nurbandiyah, & & $\mathrm{Cu}$ \\
\hline & Minarti, S.Pd & 75 & Bai \\
\hline & Nurhariyasni, & 70 , & Bai \\
\hline & $\mathrm{S}_{\mathrm{Pd}}$ Eva Yusmarni, & 79 & Bai \\
\hline & S.Pd Irvan Hilmawan, & $7^{66}$ & $\mathrm{Cu}$ \\
\hline & $\begin{array}{cc}\text { ZP. } & \text { Fitri } \\
\text { Ramadhona, S.Pd } & \end{array}$ & 75 & Bai \\
\hline 0 & Denovaldi, S.Pd & 75 & Bai \\
\hline & Jumlah & $\mathrm{a}^{72}$ & \\
\hline & Rata-rata & $0^{72,}$ & Bai \\
\hline
\end{tabular}

Jurnal JIPS (Jurnal Ilmiah Pendidikan Scholastic) Vol. 4 No. 3 (2020) ISSN : 2579-5449

This work is licensed under a Creative Commons Attribution-NonCommercial 4.0 International License. 


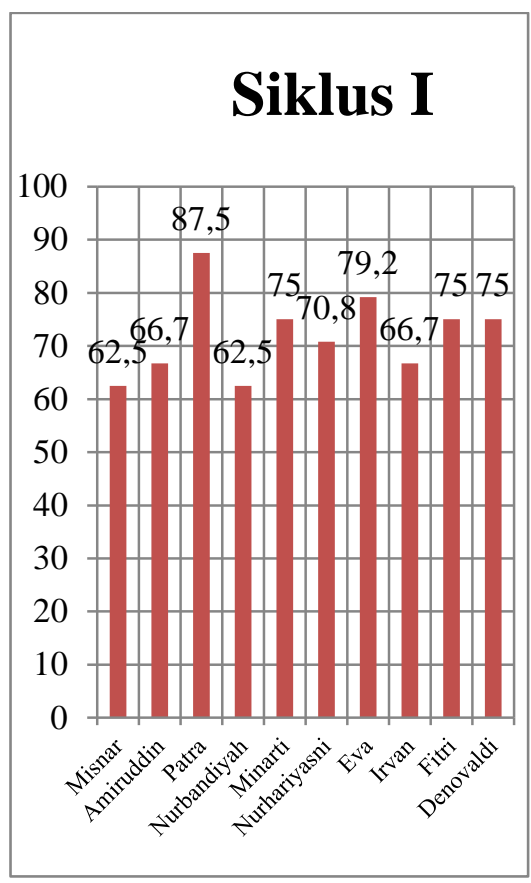

1. Deskripsi Siklus II

Kegiatan siklus II sama halnya dengan tahap siklus I yaitunya dilakukan dengan 4 tahapan metode, berikut uraian pada kegiatan siklus II:

a.Perencanaan

Pada tahap perencanaan siklus II, peneliti sama halnya dilakukan kegiatan tahap sebelumnya, yaitu pada tahap siklus II ini peneliti mempesiapkan kembali alat-alat yang dibutuhkan pada saat proses pelatihan, selanjut membuat istrumen pengamatan terhadap kemampuan guru dan juga lembar wawancara .
b.
Pelaksanaan

Pada tahap siklus II indikator pencapaian hasil dari setiap indikator pengukuran kemampuan peserta sudah adanya peningkatan dan dikategorikan sudah sangat memenuhi sesuai indikator pencapaian hasil.

\section{c.Observasi}

Observasi pada kegiatan ini dilakukan pada hari selasa tanggal 24 Maret 2020, dari semua guru yang ditinjau dari pelaksanaan kegiatan tahap siklus II semua guru sudah mampu berkreasi sekaligus alat peraga matematika yang dibuatnya sudah sesuai dengan matei pembelajaran. Berikut hasil pada pelaksanaan tahapan siklus I disajikan pada tabel 4.2 .

\section{Tabel 4.2 Hasil Kegiatan Tahap Siklus} II

\begin{tabular}{|c|c|c|c|}
\hline $\mathbf{0}$ & Nama Guru & $\mathbf{a i}^{\mathbf{N i l}}$ & $\begin{array}{l}\text { Klas } \\
\text { ifikasi }\end{array}$ \\
\hline & Musnar, & 91, & $\mathrm{Sa}$ \\
\hline & $\begin{array}{l}A \times \mathbf{M} \times \mathbf{D A} \\
\text { Amiruddin }\end{array}$ & 95, & $\mathrm{Sa}$ \\
\hline & Syarif, A.Ma.Pd & 8 & ngat Baik \\
\hline & Patra, S.Pd & 95 , & $\mathrm{Sa}$ \\
\hline & Nurbandiyah, & 91 & $\mathrm{Sa}$ \\
\hline & Minarti, S.Pd & 10 & San \\
\hline & Nurharivasni & $n_{91}$ & oat Raik \\
\hline & $\mathrm{SPd}$ & & noat Raik \\
\hline & S Pd & 85 & $\begin{array}{r}\mathrm{Sa} \\
\mathrm{Bai}\end{array}$ \\
\hline & S.Pd Irvan Hilmawan, & 791 & $\begin{array}{r}\text { Sa } \\
\text { ngat Baik }\end{array}$ \\
\hline & Fitri & 10 & $\mathrm{Sa}$ \\
\hline & Ramadhona, S.Pd & 0 & ngat Baik \\
\hline & Denovaldi, S.Pd & 91, & $\mathrm{Sa}$ \\
\hline 0 & & & ngat Baik \\
\hline & Jumlah & 94 & \\
\hline & Rata-rata & 5894 & $\begin{array}{r}\text { Sa } \\
\text { noat Raik }\end{array}$ \\
\hline
\end{tabular}

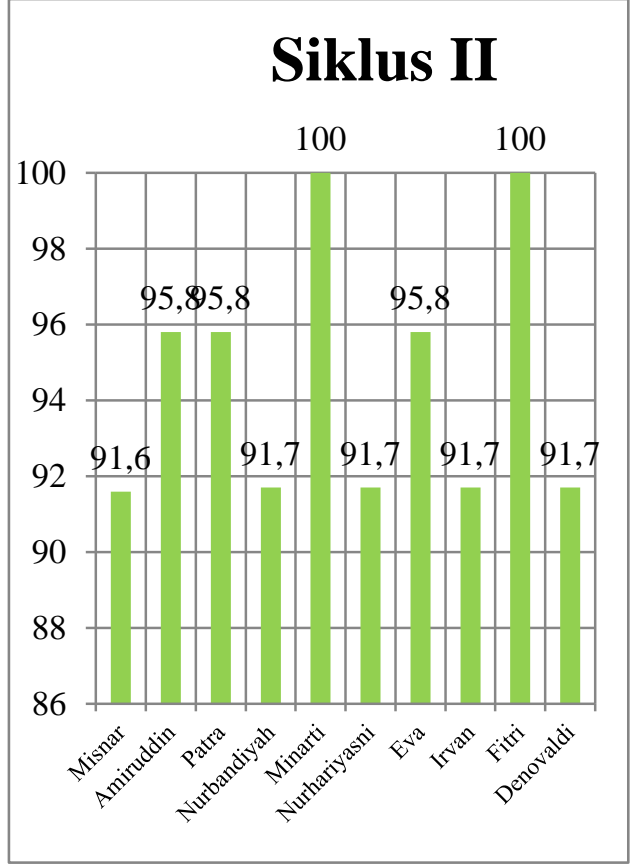

d. Tindak Lanjut

Kegiatan penelitian dalam menggunakan alat peraga matematika dengan menggunakan bahan bekas sudah sesuai dengan yang diharapkan. Semua guru sudah mampu menentukan alat peraga matematika apa yang akan dibuat sesuai dengan materi pembelajarannya.

Jurnal JIPS (Jurnal Ilmiah Pendidikan Scholastic) Vol. 4 No. 3 (2020) ISSN : 2579-5449

This work is licensed under a Creative Commons Attribution-NonCommercial 4.0 International License. 
A. Pembahasan

Penelitian Tindakan Sekolah dilaksanakan di SDN 06 Timpeh Kecamatan Timpeh Kabupaten Dharmasraya yang merupakan sekolah binaan peneliti berstatus negeri, terdiri atas delapan guru, dan dilaksanakan dalam dua siklus. Semua guru tersebut menunjukkan sikap yang baik dan termotivasi saat mengikuti pelaksanaan kegiatan dalam mempergunakan media pembelajaran. Setelah dilakukan tindakan pada siklus 1 dan siklus 2 menunjukkan hasil sebagai berikut.

Tabel 4.3.

Hasil Kegiatan Mempergunakan Media Pembelajaran Siklus I dan Siklus II

\begin{tabular}{|c|c|c|c|}
\hline $\mathbf{0}$ & Nama Guru & $\begin{array}{r}\mathrm{S} \\
\text { iklus } 1 \\
\end{array}$ & $\begin{array}{r}\text { Si } \\
\text { klus } 2\end{array}$ \\
\hline & $\begin{array}{l}\text { Musnar, } \\
\text { A.Ma.Pd }\end{array}$ & $2,5^{6}$ & $1,6^{9}$ \\
\hline & $\begin{array}{l}\text { Amiruddin } \\
\text { Syarif, A.Ma.Pd }\end{array}$ & $6,7^{6}$ & $5,8^{9}$ \\
\hline & Patra, S.Pd & $7,5^{8}$ & $5,8^{9}$ \\
\hline & $\begin{array}{l}\text { Nurbandiyah, } \\
\text { S.Pd }\end{array}$ & $2,5^{6}$ & $1,7^{9}$ \\
\hline & Minarti, S.Pd & $5^{7}$ & $00^{1}$ \\
\hline & $\begin{array}{ll}\text { Nurhariyasni, } \\
\text { S.Pd }\end{array}$ & $0,8^{7}$ & $1,7^{9}$ \\
\hline & $\begin{array}{lll}\text { Eva } & \text { Yusmarni, } \\
\text { S.Pd } & & \\
\end{array}$ & $9,2^{7}$ & $5,8^{9}$ \\
\hline & Irvan Hilmawan, & 6 & 9 \\
\hline
\end{tabular}

\section{CONCLUSION}

Dari hasil kegiatan Penelitian Tindakan Sekolah yang dilakukan pada SDN 06 Timpeh, dapat ditarik kesimpulan yaitu :

1. Berdampak positif terhadap kreativitas guru dalam memanfaatkan alat peraga pada proses pembelajaran matematika.

2. Bertambahnya kemampuan guru dalam pelaksanaan kegiatan proses pembelajaran yang kreatif, edukatif dan inovatif setelah terlaksananya kegiatan pelatihan penggunaan alat peraga matematika.

3. Pemanfaatan alat peraga matematika dapat dijadikan media dalam pembelajaran dengan memperhatikan kebutuhan siswa. Menyesuaikan media dengan materi yang

\begin{tabular}{|c|c|c|c|}
\hline & S.Pd & 6,7 & 1,7 \\
\hline & $\begin{array}{cc}\text { ZP. } & \text { Fitri } \\
\text { Ramadhona, S.Pd } & \end{array}$ & $5^{7}$ & $00^{1}$ \\
\hline 0 & Denovaldi, S.Pd & $5^{7}$ & $1,7^{9}$ \\
\hline & Jumlah Total & $20,9^{7}$ & $45,8^{9}$ \\
\hline & $\begin{array}{l}\text { Skor } \\
\text { vidu }\end{array}$ & $2,09^{7}$ & $4,58^{9}$ \\
\hline & Skor Maksimum & $000^{1}$ & $000^{1}$ \\
\hline
\end{tabular}

\section{Analisis Data Deskriptif Kuantitatif}

1. Pencapaian Peningkatan mutu guru dalam mempegunakan media pembelajaran siklus I;

$$
=\underline{720,9} \times 100 \%=72,09 \%
$$

2. Pencapaian peningkatan mutu guru dalam mempergunakan media pembelajaran tahap siklus II

$$
=\frac{945,8}{1000} \times 100 \%=94,58 \%
$$

Dari hasil analisis tersebut dapat disimpulkan bahwa terjadi peningkatan mutu guru dalam proses pembelajaran setelah diberi pembinaan melalui workshop yaitu peningkatan dari $72,09 \%$ menjadi $94.58 \%$ ada kenaikan sebesar $22,49 \%$

akan disampaikan. Dan harapan yang diinginkan dari pembelajaran tersebut. Guru dapat memilih dan membuat media sederhana dari alat peraga matematika yang ada disekitar lingkungannya.

4. Media sederhana dari alat peraga matematika cukup efektif untuk membantu siswa memahami materi yang disampaikan guru, mereka bisa belajar sambil berkarya. Selain belajar mereka juga bisa mengembangkan kemampuannya menuangkan ide dan mengembangkan kreativitasnya karena ikut serta dalam pembuatan media tersebut.

Diharapkan agar kepada guru yang telah mengikuti pelatihan dalam menggunakan alat peraga matematika, agar dapat selalu 
Basuki

Jurnal JIPS (Jurnal Ilmiah Pendidikan Scholastic) Vol. 4 No. 3 (2020) ISSN : 2579-5449

meningkatkan kemampuannya walaupun telah Agar dapat memanfaatkan ilmu yang telah selesai dilaksanakannya kegiatan pelatihan. diperoleh dari kegiatan pelatihan menggunakan alat peraga matematika

Jurnal JIPS (Jurnal Ilmiah Pendidikan Scholastic) Vol. 4 No. 3 (2020) ISSN : 2579-5449 


\section{Bibliography}

[1]Abdul Majid. (2005). Perencanaan Pembelajaran Mengembangkan Standar Kompetensi Guru. Bandung: Remaja Rosdakarya.

[2]Alfaris, Sujoko, 2012. "Peningkatan Kemampuan Guru Mata Pelajaran Melalui In House Training", Jurnal Pendidikan Penambur-No.18 tahun ke-11/Juni 27

[3]Arikunto, Suharsimi, Prosedur Penelitian : Suatu Pendekatan Praktik, Edisi Revisi VI, Jakarta : PT Rineka Cipta, 2006.

[4]Dessler, Gary. (1997). Manajemen Sumberdaya Manusia. Jakarta : PT. Prenhallindo.

[5]Estiningsih, Elly. (1994). Penggunaan Alat Peraga dalam Pengajar MatematikaSD. Yogyakarta: PPPG Matematika

[6]Hermawan, H. 2007. Media Pembelajaran $S D$. Bandung: Upi Press

[7]Meldona. 2009. Manajemen Sumber Daya Manusia Perspektif Integratif. UIN Malang Press. Malang
[8]Moh. Uzer Usman. 2005. Menjadi Guru Profesional. Bandung : Remaja Rosdakarya.

[9]Noe et al. 2008, Manajemen Sumber Daya Manusia Mencapai Keunggulan Bersaing, Salemba Empat, Jakarta

[10]Ramlan. 2012, Morfologi Suatu Tinjauan Deskriptif. Yogyakarta: CV. Karyono

[11]Ruseffendi, E.T. 1998. Dasar-dasar Penelitian Pendidikan dan Bidang No Eksakta Lainnya. Semarang: IKIP Semarang Press

[12]Sudarsono, FX. 1999. Prinsip-prinsip Penelitian Tindakan. Makalah untuk Penataran Dosen, Lembaga Penelitian IKIP Yogyakarta.

[13]Sundayana, R. 2014, Media dan Alat Peraga Dalam Pembelajaran Matematika. Bandung: Alfabeta

[14]Sutrisno, Edi. 2009. Manajemen Sumber Daya Manusia Edisi pertama. Jakarta: Kencana Prenada Media Group 